\title{
Selecting equipment using a hybrid of AHP and PROMETHEE
}

\author{
Mohammad Sadegh Horri ${ }^{\mathrm{a}}$ and Porya Moradi ${ }^{\mathrm{b}}$
}

${ }^{a}$ Member of Management Department, Islamic Azad University, Arak Branch, Arak, Iran

${ }^{b}$ M.A. in Industrial Management, Islamic Azad University, Arak Branch, Arak, Iran

\section{H R O N I C L E}

\section{Article history:}

Received January 19, 2013

Received in revised format 29 April 2013

Accepted 1 May 2013

Available online

May 22013

Keywords:

PROMETHEE

Analytical hierarchy process

Equipment selection

\section{A B S T R A C T}

Having appropriate technology is an important managerial decision in today's manufacturing industry and to choose a good technology, we need to consider various alternatives. In other words, when we intend to purchase a technology, we need to go beyond price as a primary criterion and look for other important factors such as technical support, quality, powers, etc. In this paper, we present two methods including preference ranking organization method for enrichment evaluations (PROMETHEE) and analytical hierarchy process (AHP) to rank different manufacturing facilities based on various criteria including price, weight, power, etc. and analyze the results. The proposed study of this paper considers six criteria including price, weight, power, spindle, diameter and stroke for selection of a manufacturing equipment. The results of our survey have shown that diameter and weight are number priority for ranking different alternatives.

\section{Introduction}

Having appropriate technology plays an important role in today's manufacturing industry and to choose a good technology, we need to consider various alternatives. In other words, when we intend to purchase a technology, we need to go beyond price as a primary criterion and look at other important factors such as technical support, quality, powers, etc. There are literally many different applications where an equipment is selected using multiple criteria decision making approach. According to Karande and Chakraborty (2012), with ever increasing demand for manufactured products of hard alloys and metals with high surface finish and complex shape geometry, more attention is devoted to non-traditional machining (NTM) processes, where energy in its direct form is implemented to remove material from workpiece surface. Compared with conventional machining processes, NTM processes maintain unlimited abilities and implementing NTM processes would go on increasing in diverse range of practical applications. Presence of a huge number of NTM processes

\footnotetext{
*Corresponding author

E-mail addresses: porya_m63@yahoo.com (P. Moradi) 
along with complex characteristics in NTM process selection domain compel for development of a structured method for NTM process selection for a given machining application.

Karande and Chakraborty (2012) considered four NTM process selection problems by using an integrated PROMETHEE (preference ranking organization method for enrichment evaluation) and GAIA (geometrical analysis for interactive aid), method which could act as a visual decision help to the process engineers. Cheshmberah et al. (2011) presented a multi criteria decision-making method to find a suitable solution for outsourcing activities called preference ranking organization method for enrichment evaluations (PROMETHEE). They used fuzzy numbers to determine the relative importance of different criteria and they implemented the proposed method for a real-world case study of aerospace industry. Barzinpour et al. (2011) presented an integrated balanced score card system with an adaptation of ELECTRE III method to select suitable resources for outsourcing and implemented their method for a real-world case study of subway system in Iran and the results are discussed. Mazdeh and Hamedani (2012) compared the relative importance of four major activities including educational activities, research and development, administration and services using multicriteria decision making method. Chakladar and Chakraborty (2008) presented a combined TOPSISAHP-method-based approach for non-traditional machining processes selection. Chakladar et al. (2009) provided a digraph-based expert system for non-traditional machining processes selection. Chakraborty (2011) provided an applications of the MOORA method for decision making in manufacturing environment. Das and Chakraborty (2011) considered selection of non-traditional machining processes using analytic network process.

\section{PROMETHEE method}

The PROMETHEE techniques, including PROMETHEE I for partial ranking of the alternatives and PROMETHEE II for a comprehensive ranking of the alternatives, were developed by Brans (Brans \& Vincke, 1985; Brans et al. 1986; Brans \& Mareschal, 1994). Thereafter, different versions of PROMETHEE method, like PROMETHEE III for ranking based on interval, PROMETHEE IV for ranking of the alternatives were developed for solving more complex decision-making problems. In the area of decision-making, PROMETHEE techniques have become quite popular because of their simpler mathematical advantages and user friendliness (De Keyser \& Peeters, 1996; Behzadian et al., 2010). The PROMETHEE method begins with the following decision matrix:

$$
\left[\begin{array}{cccccc}
g_{l}\left(a_{1}\right) & g_{2}\left(a_{1}\right) & \ldots & g_{j}\left(a_{1}\right) & \ldots & g_{n}\left(a_{1}\right) \\
g_{l}\left(a_{2}\right) & g_{2}\left(a_{2}\right) & \ldots & g_{j}\left(a_{2}\right) & \ldots & g_{n}\left(a_{2}\right) \\
\ldots & \ldots & \ldots & \ldots & \ldots & \ldots \\
g_{l}\left(a_{i}\right) & g_{2}\left(a_{i}\right) & \ldots & g_{j}\left(a_{i}\right) & \ldots & g_{n}\left(a_{i}\right) \\
\ldots & \ldots & \ldots & \ldots & \ldots & \ldots \\
g_{l}\left(a_{m}\right) & g_{2}\left(a_{m}\right) & \ldots & g_{j}\left(a_{m}\right) & \ldots & g_{n}\left(a_{m}\right)
\end{array}\right]
$$

where $g_{j}\left(a_{i}\right)$ is the performance of $i^{\text {th }}$ alternative on $j^{\text {th }}$ criterion, $m$ is the number of alternatives and $n$ is the number of criteria. The preference structure of PROMETHEE technique is based on pair-wise comparisons, where the deviation between the evaluations of two alternatives on a specific criterion is taken into account. Here larger deviation means larger preference. These preferences normally range between 0 and 1 . For each criterion, the following preference function is developed

$P_{j}(a, b)=F_{j}\left[d_{j}(a, b)\right] \quad \forall a, b \in A$

where $d_{j}(a, b)=\left[\mathrm{g}_{j}(a)-\mathrm{g}_{j}(b)\right]$ and $0 \leq P_{j}(a, b) \leq 1$.

For beneficial criteria where the higher values are desired this function yields the preference of alternative ' $a$ ' over alternative ' $b$ ' for the observed deviations among their evaluations on $j$ 'th criterion. 
The preference is set to 0 when the deviations are negative. For non-beneficial criteria where lower values are desired, the preference function can be rewritten as follows:

$$
P_{j}(a, b)=F_{j}\left[-d_{j}(a, b)\right]
$$

There are six basic kinds of preference function, i.e. usual criterion, U-shape criterion, V-shape criterion, level shape criterion, V-shape with indifference criterion and Gaussian criterion, which can be used by decision maker. For some of these preference functions, different threshold parameters $(p$, $q$ or $s$ ) must be specified by the decision maker, which constrains their applications. Among these preference functions, usual criterion appears to be the simplest one. For the application of PROMETHEE technique, the evaluation/decision matrix $\mathrm{g}_{j}($.$) , the relative importance (weight) of j^{\text {th }}$ criterion $\left(w_{j}\right)$ and the generalized criterion, $\left\{\mathrm{g}_{j}(),. P_{j}(a, b)\right\}$ have to be defined. PROMETHEE I method is based on pair-wise comparisons where the preference indices are defined as follows:

$$
\left\{\begin{array}{l}
\pi(a, b)=\sum_{j=1}^{n} w_{j} P_{j}(a, b) \\
\pi(b, a)=\sum_{j=1}^{n} w_{j} P_{j}(b, a)
\end{array}\right.
$$

where $\pi(a, b)$ measures the degree in which ' $a$ ' is preferred to ' $b$ ' over all the criteria and $\pi(b, a)$ stands for the preference of ' $b$ ' against ' $a$ '. In most of the decision-making problems, there are some criteria in which ' $a$ ' yields better than ' $b$ ', and criteria in which ' $b$ ' yields better than ' $a$ ', and thus, $\pi(a, b)$ and $\pi(b, a)$ are positive. When the values of $\pi(a, b)$ and $\pi(b, a)$ are measured for each pair of alternatives in the decision matrix, a complete outranking relation graph is obtained. Here, each alternative ' $a$ ' represents exactly $(m-1)$ number of other alternatives in the decision matrix. Now, the positive and the negative outranking flows are specified as below:

Positive outranking flow, $\varphi^{+}(a)=\frac{1}{m-1} \sum_{x \in A} \pi(a, x)$

Negative outranking flow, $\varphi^{-}(a)=\frac{1}{m-1} \sum_{x \in A} \pi(x, a)$

The positive outranking flow shows how an alternative ' $a$ ' outranks all the other alternatives. The higher the value of $\varphi^{+}(a)$, the better the alternative is. The negative outranking flow means how an alternative ' $a$ ' is outranked by all other alternatives. Lower value of $\varphi^{-}(a)$ leads us to have better alternative. In PROMETHEE I technique, the partial ranking of the alternatives is derived from the positive and negative outranking flows. Both flows do not normally provide the same rankings. On the other hand, PROMETHEE II technique provides a complete preorder of the alternatives while using a net flow, although it is possible to lose some information on the preference relations. Here, there is a tradeoff between the positive and negative outranking flows. The net outranking flow for each alternative is obtained from the following expression:

$\varphi(a)=\varphi^{+}(a)-\varphi^{-}(a)$

A higher value of $\varphi(a)$ means better alternative. Thus, the best alternative has always the highest $\varphi(a)$ value. From the positive and negative outranking flows, the net outranking flow value is reformulated, as follows:

$\varphi(a)=\varphi^{+}(a)-\varphi^{-}(a)=\frac{1}{m-1} \sum_{j=1}^{n} \sum_{x \in A}\left[P_{j}(a, x)-P_{j}(x, a)\right] w_{j}$

Thus,

$\varphi(a)=\sum_{j=1}^{n} w_{j} \varphi_{j}(a)$

if $\varphi_{j}(a)=\frac{1}{m-1} \sum_{x \in A}\left[P_{j}(a, x)-P_{j}(x, a)\right]$ 
where $\varphi_{j}(a)$ is the single criterion net flow obtained for $j^{\text {th }}$ criterion. Note that the global net flow of an alternative is the scalar product of vector of the criteria weights and profile vector of that alternative. Analytical hierarchy process (AHP) is another method, which is used for the case study of this paper. Saaty (1994) is believed to be the first who introduced this pair-wise comparison technique and it has been widely used in various applications in different areas of manufacturing and equipment selection strategies.

\section{The Case study}

The proposed study of this paper considers six criteria including price, weight, power, spindle, diameter and stroke for selection of a manufacturing equipment. Table 1 shows details of pair-wise comparison of these criteria and ranking of these criteria using Expert Software package. The consistency ratio is equal to 0.07 , which is less than 0.1 and it means the ranking results are consistent.

Table 1

The results of pair-wise comparison

\begin{tabular}{cccccccc}
\hline Criteria & Price & Weight & Power & Spindle & Diameter & Stroke & Rank \\
\hline Price & 1 & 0.54 & 0.60 & 0.42 & 0.54 & 0.58 & 0.089 \\
Weight & 1.85 & 1 & 2.7 & 1.20 & 1.20 & 2.40 & 0.240 \\
Power & 1.67 & 0.37 & 1 & 0.39 & 0.42 & 1.63 & 0.117 \\
Spindle & 2.38 & 0.84 & 2.56 & 1 & 0.41 & 0.47 & 0.161 \\
Diameter & 1.85 & 0.84 & 2.38 & 2.44 & 1 & 2.40 & 0.252 \\
Stroke & 1.72 & 0.41 & 0.61 & 2.13 & 0.42 & 1 & 0.141 \\
\hline
\end{tabular}

For the implementation of PROMETHEE, we consider five alternatives where their technical characteristics are summarized in Table 2 as follows,

Table 2

The summary of technical characteristics

\begin{tabular}{ccccccc}
\hline & Price & Weight & Power & Spindle & Diameter & Stroke \\
Max & Max & Max & Max \\
Max/Min & Min & 0.240 & 0.117 & 0.161 & 0.252 & 0.141 \\
\hline Weight & 0.089 & 2.65 & 130 & 1440 & 75 & 75 \\
Machine 1 & 280 & 2.12 & 55 & 1450 & 50 & 80 \\
Machine 2 & 250 & 1.85 & 40 & 1400 & 100 & 75 \\
Machine 3 & 280 & 2.85 & 75 & 2000 & 27 & 110 \\
Machine 4 & 270 & 2.70 & 120 & 2880 & 100 & 75 \\
Machine 5 & 310 & & & & & \\
\hline
\end{tabular}

Before we use PROMETHEE, we need to choose appropriate preference numbers. Table 3 summarizes the results of our survey.

Table 3

The summary of preference numbers associated with five machines

\begin{tabular}{ccccc}
\hline Criteria & & $\mathrm{q}$ & $\mathrm{p}$ & $\mathrm{s}$ \\
\hline Price & Level & 200 & 200 & - \\
Weight & Gaussian & - & - & 2 \\
Power & Level & 80 & 120 & - \\
Spindle & Level & 1500 & - & - \\
Diameter & Gaussian & - & 800 & 70 \\
Stroke & V-shape & - & & - \\
\hline
\end{tabular}

We have implemented Visual PROMETHEE to rank different alternatives and Fig. 1 demonstrates the results of our survey. 


\begin{tabular}{|c|c|c|c|c|c|c|c|}
\hline & & 目 & D & 目 & 目 & 目 & 目 \\
\hline & \begin{tabular}{|c|} 
Scenario1 \\
\end{tabular} & \begin{tabular}{|l|} 
Price \\
\end{tabular} & Weight & Power & Spindle & \begin{tabular}{|c|} 
Diameter \\
\end{tabular} & Stroke \\
\hline & Unit & $\$$ & ton & kwatt & $\mathrm{rpm} / \mathrm{min}$ & $\mathrm{mm}$ & $\mathrm{mm}$ \\
\hline & Cluster/Group & $>$ & 8 & & & $>$ & \\
\hline & Preferences & & & & & & \\
\hline & Min/Max & $\min$ & $\min$ & $\max$ & $\max$ & $\max$ & $\max$ \\
\hline & Weight & 0,09 & 0,24 & 0,12 & 0,16 & 0,25 & 0,14 \\
\hline & Preference Fn. & Level & Gaussian & Level & Level & Gaussian & V-shape \\
\hline & Thresholds & absolute & absolute & absolute & absolute & absolute & absolute \\
\hline & -Q: Indifference & 200,00 & $\mathrm{n} / \mathrm{a}$ & 80,00 & 1500,00 & $\mathrm{n} / \mathrm{a}$ & $\mathrm{n} / \mathrm{a}$ \\
\hline & -P: Preference & 300,00 & $\mathrm{n} / \mathrm{a}$ & 120,00 & 1800,00 & $\mathrm{n} / \mathrm{a}$ & 80,00 \\
\hline & -S: Gaussian & $\mathrm{n} / \mathrm{a}$ & 2,00 & $\mathrm{n} / \mathrm{a}$ & $\mathrm{n} / \mathrm{a}$ & 70,00 & $\mathrm{n} / \mathrm{a}$ \\
\hline & Statistics & & & & & & \\
\hline & Minimum & 250,00 & 1,85 & 40,00 & 1400,00 & 27,00 & 75,00 \\
\hline & Maximum & 310,00 & 2,85 & 130,00 & 2880,00 & 100,00 & 110,00 \\
\hline & Average & 278,00 & 2,43 & 84,00 & 1834,00 & 70,40 & 83,00 \\
\hline & Standard Dev. & 19,39 & 0,38 & 35,41 & 567,93 & 28,54 & 13,64 \\
\hline & Evaluations & & & & & & \\
\hline 可 & MM1 & 280,00 & 2,65 & 130,00 & 1440,00 & 75,00 & 75,00 \\
\hline D & MM2 & 250,00 & 2,12 & 55,00 & 1450,00 & 50,00 & 80,00 \\
\hline D & MM3 & 280,00 & 1,85 & 40,00 & 1400,00 & 100,00 & 75,00 \\
\hline D & MM4 & 270,00 & 2,85 & 75,00 & 2000,00 & 27,00 & 110,00 \\
\hline 可 & MM5 $\square$ & 310,00 & 2,70 & 120,00 & 2880,00 & 100,00 & 75,00 \\
\hline
\end{tabular}

Fig. 1. The results of Visual PROMETHEE

In addition, Fig. 2 demonstrates details of the positions of five alternatives.

\begin{tabular}{|c|c|c|c|c|c|c|c|c|}
\hline & Phit & Phi- & Phi & \multirow{3}{*}{ ind } & \multirow{3}{*}{ and } & \multirow{3}{*}{$=$} & \multirow{3}{*}{$=$} & \multirow{3}{*}{$\sum$} \\
\hline MM1 & 0,0320 & 0,0321 & $-0,0001$ & & & & & \\
\hline MM2 & 0,0185 & 0,0460 & $-0,0275$ & & & & & \\
\hline MM3 & 0,0619 & 0,0323 & 0,0296 & & ins & $9+1$ & 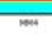 & 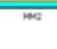 \\
\hline MM4 & 0,0595 & 0,0808 & $-0,0213$ & & & & & \\
\hline MM5 & 0,0447 & 0,0253 & 0,0193 & $=$ & $=$ & $=$ & $=$ & $=$ \\
\hline
\end{tabular}

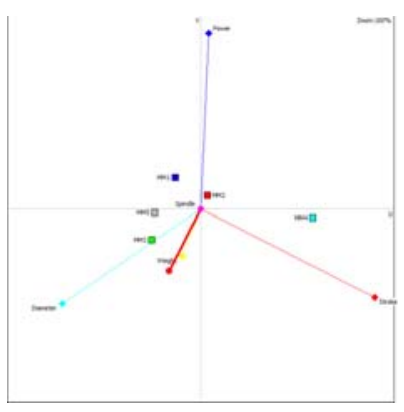

Fig. 2. The results of ranking using Visual PROMETHEE 


\section{Discussion and Conclusion}

In this paper, we have presented an empirical investigation to rank different manufacturing equipment based on the implementation of PROMETHEE and AHP techniques. The proposed model has considered six criteria including price, weight, power, spindle, diameter and stroke for selection of a manufacturing equipment. The results of our survey have shown that diameter and weight are number priority for ranking different alternatives. The proposed model of this paper can be implemented for many real-world applications and it can help managers find better decisions.

\section{References}

Barzinpour, F., Namazifard, S \& Makui, A. (2011). An integrated framework for outsourcing using balanced score card and ELECTRE III. Management Science Letters, 1(2), 99-106.

Behzadian, M., Kazemzadeh, R.B., Albadvi, A., \& Aghdasi, M. (2010). PROMETHEE: A comprehensive literature review on methodologies and applications. European Journal of Operational Research, 200, 198-215.

Brans, J.P., \& Vincke, P. (1985). A preference ranking organisation method: The PROMETHEE method for MCDM. Management Science, 31, 647-56.

Brans, J.P., Vincke, P., \& Mareschal, B. (1986). How to select and how to rank projects: The PROMETHEE method. European Journal of Operational Research, 24, 228-38.

Brans, J.P., \& Mareschal, B. (1994). The Promcalc and Gaia decision-support system for multicriteria decision aid. Decision Support Systems, 12, 297-310.

Chakladar, N.D., \& Chakraborty, S. (2008). A combined TOPSIS-AHP-method-based approach for non-traditional machining processes selection. Proc. IMechE Part B: Journal of Engineering Manufacture, 222, 1613-1623.

Chakladar, N.D., Das, R., \& Chakraborty, S. (2009). A digraph-based expert system for nontraditional machining processes selection. International Journal of Advanced Manufacturing Technology, 43, 226-237.

Chakraborty, S., \& Dey, S. (2006). Design of an analytic-hierarchy-process-based expert system for non-traditional machining process selection. International Journal of Advanced Manufacturing Technology, 31, 490-500.

Chakrabarti, S., Mitra, S., \& Bhattacharyya, B. (2007). Development of a management information system as knowledge base model for machining process characterization. International Journal of Advanced Manufacturing Technology, 34, 1088-1097.

Chakraborty, S., \& Dey, S. (2007). QFD-based expert system for non-traditional machining processes selection. Expert Systems with Applications, 32, 1208-1217.

Chakraborty, S. (2011). Applications of the MOORA method for decision making in manufacturing environment. International Journal of Advanced Manufacturing Technology, 54, 1155-1166.

Cheshmberah, M., Makui, A \& Seyedhoseini, S. (2011). A new fuzzy MCDA framework for makeor-buy decisions: A case study of aerospace industry. Management Science Letters, 1(3), 323-330.

Das, S., \& Chakraborty, S. (2011). Selection of non-traditional machining processes using analytic network process. Journal of Manufacturing Systems, 30, 41-53.

De Keyser W., \& Peeters, P. (1996). A note on the use of PROMETHEE multicriteria methods. European Journal of Operational Research, 89, 457-461.

Karande, P \& Chakraborty, S. (2012). Application of PROMETHEE-GAIA method for nontraditional machining processes selection. Management Science Letters, 2(6), 2049-2060.

Mazdeh, M \& Hamedani, M. (2012). A new outsourcing framework: A case study of educational institution activities. Management Science Letters, 2(3), 1005-1010.

Saaty, T.L. (1994). Fundamentals of decision making and priority theory with the analytical hierarchy process. RWS Publications, Pittsburgh, PA. 